\title{
LA NARRATIVA SONORA DE LUIS RAFAEL SÁNCHEZ
}

\author{
THE AUDible NARRATIVE OF LUIS RAFAEL SÁNCHEZ
}

\section{VALERIA DE LOS RÍOS²}

\section{RESUMEN}

Este artículo explora el carácter sonoro de la novela La guaracha del Macho Camacho del puertorriqueño Luis Rafael Sánchez. En ella, la escritura intenta imitar a la radio, por ejemplo, a través de la inclusión del discurso de un disc-jockey, quien anuncia con insistencia el éxito de la guaracha "La vida es una cosa fenomenal". La utilización del modelo radial, que apela a la intimidad de las masas no letradas, contribuye a construir a los sujetos y evidencia la estandarización presente en los discursos de los personajes. Al mismo tiempo, apunta a la construcción potencial de una comunidad a partir de los medios masivos.

Palabras clave: Luis Rafael Sánchez, La guaracha del Macho Camacho, radio, cultura masiva.

\section{ABSTRACT}

This article explores the audible character of the novel La guaracha del Macho Camacho by the Puerto Rican author Luis Rafael Sánchez. In this novel, writing imitates radio, for example through the inclusion of the discourse of a disc-jockey, a character who announces with insistence the success of the guaracha "La vida es una cosa fenomenal". The employment of the radio model -which appeals to the intimacy of the illiterate

\footnotetext{
${ }^{1}$ Este trabajo forma parte del proyecto Fondecyt № 3085038 "Literatura latinoamericana y tecnología”.

${ }^{2}$ Universidad de Santiago de Chile (USACH). Santiago, Chile. E-mail: valeria.delosrios@ usach.cl
} 
masses-contributes to the construction of the subjects and reveals the standardization present in the discourse of the characters. At the same time, it points to the potential construction of a community based on mass media culture.

Keywords: Luis Rafael Sánchez, La guaracha del Macho Camacho, radio, mass media culture.

Recibido: 05.11.09. Aceptado: 10.05.10.

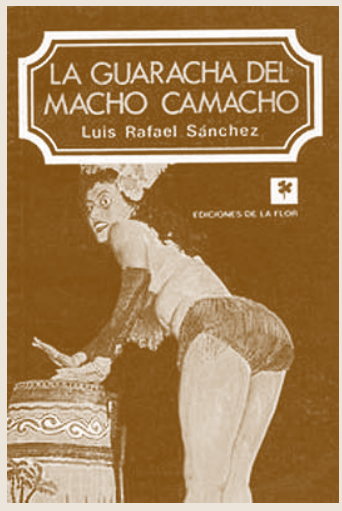

T A guaracha del Macho Camacho, de 1976, del puertorriqueño Luis Rafael Sánchez incorpora en su construcción, de manera lúdica y a la vez vanguardista, la música, el medio radiofónico, el cine y la televisión, así como diversas expresiones de la cultura popular. La novela sitúa su red discursiva en un día miércoles en la ciudad de San Juan, en Puerto Rico, en el que la vida de seis personajes se desarrolla normalmente, con cruces, desencuentros y choques, estos últimos, tanto metafóricos como en el sentido literal. Los episodios están permanentemente interrumpidos por una transmisión radial de la "Discoteca Popular", una radio local que anuncia con insistencia el éxito del momento: "La guaracha del Macho Camacho", que le da el título a la novela en su totalidad.

En Panorama de la radio de 1929 André Coeuroy divide la literatura inspirada en la radio en dos categorías: radiofónica y radiogénica. Los trabajos radiofónicos toman a la literatura como tema, pero su estructura y su lenguaje permanecen sin ser tocados por el medio. Los trabajos radiogénicos, en cambio, están escritos para la radio, y su estilo, estructura y extensión son adecuados a las características del medio (Gallo, 2005: 157). Sin duda, la novela de Sánchez es un ejemplo paradigmático de esta última categoría. Para apreciar más claramente el carácter radiogénico de la novela de Sánchez, es necesario referirse a las intervenciones del disc-jockey. En una de ellas señala:

Y SEÑORAS Y señores, amigas y amigos, porque lo dice el respetable público y el respetable público es el que dice y digo yo lo que dice mete mieditis, continúa en el primer e indiscutible favor del respetable público, a través del primer desfile de éxitos de la radio antillana, transmitida por la primera estación radiodifusora o primera estación radioemisora del cuadrante antillano, con super antena trepada en el superpico del super país, continúa, repito para consumo de los radioyentes que (2000: 117). 
Esta cita está plagada de repeticiones y de fórmulas propias del medio radial, y se dirige a un radioyente definido, a quien se identifica como consumidor. Pero quizás lo más interesante de ella sea que termina así, in medias res, como si el discurso radiofónico hubiera sido interrumpido, o más bien, montado con el capítulo siguiente, en el que el senador Vicente Reinosa medita detenido en un taco de proporciones literarias, que el narrador compara de manera explícita con el cuento "Autopista del Sur" de Julio Cortázar. Esta cita incompleta revela que el modelo radiofónico es la base estructural de la novela, el que le da su unidad y el que estandariza los lenguajes que se incluyen en La guaracha del Macho Camacho.

La radio -como todos los medios de reproducibilidad técnica- intenta hacer transparentes su mediatización y sus propias convenciones en su esfuerzo por reproducir de manera más directa posible la realidad (Fernández 2008: 39). Su efecto más poderoso es envolver a las personas en una profundidad, en una suerte de mundo privado, incluso en medio de las multitudes propias de la vida urbana moderna (McLuhan, 1964: 260). Tal como lo afirma Marshall McLuhan, la radio afecta a las personas de manera íntima, de persona a persona, generando un efecto de experiencia privada (1964: 260). Este efecto de privacidad es el que emulan los monólogos interiores de los personajes de La guaracha del Macho Camacho, que se sienten interpelados positiva o negativamente por el tema "La vida es una cosa fenomenal" y a partir de él se constituyen como sujetos. Por ejemplo, La Madre o China Hereje siente un fanatismo por el tema del Macho Camacho. Graciela Alcántara y López de Montefrío lo rechazan abiertamente como música vulgar, mientras que Vicente y su hijo Benny se van contagiando progresivamente y de manera casi involuntaria con el virus del popular éxito radial.

En una cita más o menos extensa en que el narrador se focaliza en el personaje de La Madre/la China Hereje, ésta recuerda sus primeros encuentros sexuales con sus primos Hugo, Paco y Luis, bautizados así por su tío en honor al Pato Donald. El episodio está relatado como una secuencia cinematográfica que parece sacada de una película pornográfica de bajo presupuesto:

Secuencia de los tres macharranes cortados por la cintura a la usanza de las fotografías de las cédulas de identidad: camisas mamitoescas, gafas ahumadas, cabeza ladeada. Corte. Secuencia de los tres macharranes tendidos en una cama cubierta con colcha de motitas, cama cubierta con colcha de chenil, cama cubierta con colcha de retazos. Frente a las camas 
cubiertas con colcha de motitas, colcha de chenil, colcha de retazos un almanaque del Cafetín La Taza de Oro, Trujillo Alto, Puerto Rico. Cámara al rostro del macharrán mayor, recorrido de la cámara por la cara del macharrán mayor: barba cerrada, patilla operativa escapada del coro de las sonrisas de Luisa Fernanda, bigotazo villista, ojos brotados por el deseo. Viaje veloz de la cámara hasta las partes del macharrán mayor; estaciones recorridas: tetillas sepultadas en maraña de pelos, ombligo sepultado en maraña de pelos, partes pudibundas sepultadas en maraña de pelos. Corte. Secuencia del macharrán mayor en escalada everéstica de la autora del cerebro. Corte. Tomas intermitentes del humor llamado sudor brotando a chorros por los poros de la pareja. Corte. Plano primerísimo de un poro sudado. Corte. Plano primerísimo de un poro sudando. Corte. Toma abrasante del macharrán mayor mientras parte en dos gajos el conducto membranoso y fibroso que se extiende desde la vulva hasta la matriz de la autora del cerebro. Corte. Toma panorámica de cuerpos en convulsión culminante: interés especial en el frotado de los vientres: ombligo con ombligo: así se chicha. Corte. Toma del cuerpo del macharrán mayor mientras bicicletea con agilidad maratónica el cuerpo de la autora del cerebro. Corte. Toma panorámica del cuerpo de la autora del cerebro, cuerpo resbaloso, cuerpo vaselinado, cuerpo aceitado con bronceador Coppertone, cuerpo aceitado con fijador Johnson. Corte. Toma final de la mano de la autora del cerebro durante la ejecución de caricias desesperadas y desesperantes de la melena tarzánica del macharrán mayor (2000: 219-220).

A pesar de que el narrador está focalizado en la mente del personaje, hay un distanciamiento en su relato que produce un extrañamiento en el lector y que permite ironizar o parodiar con humor la situación. La cita es interesante por su forma, ya que imita el montaje cinematográfico a través de sus innumerables cortes, pero además porque encierra algunos de los procedimientos más recurrentes en la novela. Tal como lo nota Ilka Kressner -y en la cita anterior hay varios ejemplos de ello- en La guaracha del Macho Camacho son comunes los paralelismos fonéticos, las aliteraciones, las asonancias, las repeticiones de palabras o de unidades sintácticas. También abundan los superlativos, las rimas interiores y las asonancias múltiples (2008: 102). En la cita son mencionados además algunos elementos de la cultura popular, como un almanaque, una zarzuela y el personaje de Tarzán. Del mercado, se citan con nombre propio el bronceador Coppertone y el fijador Johnson. Esto ha llevado a autores como Joseph Chadwick a afirmar que la figura que predomina en la novela es la del fetichismo, tanto económico como sexual (1987: 70). Los objetos del mercado y los objetos culturales aparecen igualmente como mercancías, en las que el valor de uso 
es superado por el valor de cambio. Según Lidia Santos, en la novela los mismos personajes son caracterizados como meros consumidores, de allí que sean presentados como trazos a los que se les confiere escasa o nula profundidad (129).

A la cita cinematográfica leída hace algunos instantes se agrega un componente musical, cuando el narrador sugiere que al momento de editar el episodio debe agregarse, "como música incidental y accidental la guaracha del Macho Camacho La vida es una cosa fenomenal" (2000: 221). La adición del sonido al montaje visual es significativa, puesto que, tal como ha indicado Michel Chion, el sonido en el cine es "más que la imagen, un medio insidioso de manipulación afectiva y semántica" (2008: 40). Esto, porque el sonido puede interpretar el sentido de una imagen al hacernos ver en ella lo que sin él no veríamos o veríamos de otro modo. Podría afirmarse sin riesgo de exageración que la novela en su totalidad sigue el modelo recién expuesto. El narrador de la novela es una "voz móvil” (Kressner 2008: 104), capaz de entrar en la mente y en el cuerpo de los distintos personajes. Los diálogos escasean y las intervenciones de los personajes se parecen más a un monólogo interior. De este modo, la voz del narrador actúa como lo que Chion denomina el "sonido interno" en el cine, aquel que está situado en el presente de la acción, y que corresponde al interior tanto físico como mental de un personaje (2008: 78). Sin embargo, a excepción del discurso directo empleado en las intervenciones del disc-jockey, esta voz es al mismo tiempo una voz acusmática, aquella "que se oye sin ver la causa originaria del sonido" (Chion, 2008: 74), porque corresponde en gran medida al narrador y no al personaje visualizado. Esto se hace evidente sobre todo en las alusiones cultas a la literatura y al cine que hace este narrador (a autores como Flaubert, García Márquez, Stendahl, Serraute, Schwob, y a cineastas como Buñuel, Godard y de Sica, entre otros), y que parecen ajenas al dominio de la mayoría de los personajes de la novela.

Para Carlos Alonso, la conexión entre música y escritura en la novela de Sánchez es innegable, ya que en ella se usan patrones rítmicos, cadencias musicales y contrapuntos, en los que la guaracha - un tipo de canción graciosa, mezcla de son, cumbia, rumba y rock and roll, que se caracteriza por un ritmo rápido, un tono irreverente y paródico (Feliú, 2001: 227)- ocupa un sitio privilegiado. Lidia Santos va un poco más allá al anunciar que la novela funciona como el script de un hit-parade radiofónico, en el que la ciudad de San Juan aparece como un "paisaje sonoro" (2001: 132).

Uno de los factores que explica la facilidad con que prospera la guaracha entre los auditores, es que, tal como lo afirma José Luis Fernández, con la

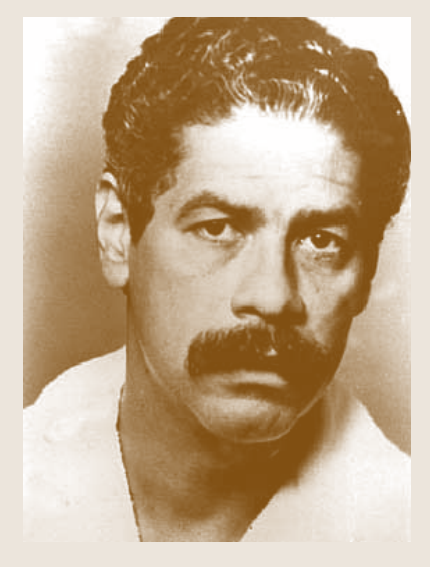

L. R. Sánchez 
radio no hace falta ser letrado, puesto que el sonido no discrimina -como el diario- a través del grado de alfabetización, de allí que la radio haya sido vista como instrumento ideal para la educación de las masas (Gallo 2005: 125). Además, la radio no sólo funciona como entretenimiento, también como información y, con respecto a ella, su ventaja comparativa en relación a otros medios es la instantaneidad. Según Fernández, recién con la radio por primera vez en un discurso mediatizado el ahora es ahora (2008: 44). Con ello, al interior del propio medio se produce una tensión entre lo que está "en vivo" y lo grabado, que se evidencia por la materialidad del sonido, la presencia o ausencia de ruido, y la utilización de un guión planeado o de un discurso improvisado. El éxito del programa radial "La guerra de los mundos" de Orson Welles, en 1938, radicó precisamente en la emulación de un programa radial interrumpido por la noticia en vivo de una invasión extraterrestre, que imitó las convenciones propias de los noticiarios radiales. En la novela de Sánchez el discurso continuo y constante del disc-jockey se ve también interrumpido por el anuncio de una noticia de último minuto: la explosión de una bomba en la Universidad de Puerto Rico. Esta noticia irrumpe en el discurso narrativo, ya que es un signo exterior a los personajes, ajeno a su vida cotidiana, al desenvolvimiento de su subjetividad y de su vida interior. Para la comunidad de oyentes, la radio es capaz de instalar ciertos hitos que se hacen comunes para todos. Tal como lo afirma Rubén Gallo siguiendo a Benedict Anderson, en países con alto grado de analfabetismo la radio se constituye desde los años 30 como el medio ideal para formar el sentimiento nacionalista (2005: 126), ya que permite imaginar una comunidad. En esa misma línea, Jesús Martín Barbero ha afirmado que la radio es un agente impulsor de identidades sociales, pero subraya que éstas responden más al nuevo modelo económico que a una renovación de la vida política (2001: 197-198).

La segunda oralidad promovida por la radio apunta a generar una comunidad social formada por una suma de individuos con un idioma común, que viven sus gustos y preferencias como elecciones personales y particulares, a pesar de estar determinados por el mercado y la cultura masiva. Esta situación ha sido analizada persistentemente como un tipo de alienación (Cruz, Chadwick), que en el caso específico de Puerto Rico está fuertemente ligada al colonialismo norteamericano, que se manifiesta a través de su estatus de "Estado Libre Asociado". Pero la cultura de masas no debe ser analizada del mismo modo que un régimen político. La producción cultural masiva no tiene un carácter puramente impositivo, y puede manifestar un componente creativo a partir de la apropiación. Lidia Santos, por ejem- 
plo, utiliza el concepto de "táctica" de Michel de Certeau para referirse a la novela. Una táctica -“el arte del débil” según De Certeau (1999: 43)- es una práctica fragmentaria, que depende de un momento determinado y oportuno. Por ejemplo, en la novela en medio del atochamiento -alegoría nacional del estancamiento- los radioescuchas se ponen a bailar:

El genterío se ha bajado de los carros, el gentío ha declarado este miércoles como día nacional de la guaracha, el genterío se remenea cuando corea la vida es una cosa fenomenal. Oficial, oficial el diagnóstico: la peste de la guaracha ha tomado el país de punta a punta: nadie escapará a la peste de la guaracha del Macho Camacho. Oficial: la guaracha del Macho Camacho es epidemia (2000: 286).

La guaracha como producto de la cultura de masas es apropiada por los oyentes a través del baile: la gente se baja de los automóviles detenidos y es capaz de moverse individualmente, pero a un mismo tiempo. La táctica aquí sería en primer lugar un regreso al cuerpo, una corporeización de lo musical que en el caso de esta novela es puramente auditivo, porque corresponde a la reproducción del disco grabado de la guaracha. Este efecto inesperado del hit radial puede ser leído también como una alegoría política, pero ésta, más que generar un efecto o resultado concreto, da cuenta de una potencia, de una posibilidad.

Como hemos visto, la radio sirve como base estructural de la novela. Pero es necesario precisar que ésta se hace presente no sólo con la inclusión del disc-jockey, sino que también a partir de la utilización de un lenguaje estandarizado (el senador Vicente Reinosa y su tick de rimar una frase de propaganda electoral cada vez que se nombra a sí mismo, por ejemplo: "Vicente es decente y su conciencia es transparente" (2000: 119), la rima con forma de publicidad con la frase "Como hace el Ace", refiriéndose al detergente (2000: 105)), o la repetición como método para capturar la atención del escucha en múltiples momentos de la novela (Fernández, 2008: 59). El discurso radiofónico permea todos los discursos al interior de La guaracha del Macho Camacho y los estandariza en relación a las convenciones propias del medio. Si bien los lenguajes de los medios naturalizan la relación entre el significado y significante, tal como lo ha notado Arnaldo Cruz, la parodia de estos lenguajes desnaturaliza esa naturalidad, revelando el mecanismo con el que operan tanto la propaganda política como la publicidad (1985: 42).

Por otra parte, el narrador de la novela recupera la oralidad de los personajes, los ubica en la escala social y con ello realiza lo que el propio Sánchez 
denomina la "legalización de la cursilería" (Santos, 2001: 130). Esta "legalización" coincide con el mecanismo de "seducción y traición" que Ana María Amar Sánchez (2000) detecta en la relación entre literatura y cultura de masas: la literatura se apropia de imágenes y convenciones de la cultura masiva (cine, telenovelas, cómics, literatura detectivesca) y este contacto con las expresiones populares supone una transformación. Pero, al mismo tiempo que la literatura tiende a borrar las jerarquías y a apropiarse de los discursos considerados "bajos", inmediatamente restituye las diferencias que distinguen a estos textos de los márgenes.

En definitiva, la novela de Sánchez se preocupa por reproducir la oralidad. Esta reproducción utiliza la radio como modelo y, dentro de ella, recupera la música y el discurso del locutor. Además, la novela da cuenta de la formación de una comunidad imaginada que se basa en el consumo y en los productos de la cultura de masas. Estos productos son apropiados por los personajes. Quizás el gesto más audaz del autor sea utilizar el mismo nombre del éxito radial como título de la novela. Este es un signo más de la parodia, porque la novela imita a la radio y se confunde con ella, y como ese medio, graba, reproduce y duplica. Esa repetición hace que ambos productos culturales se hagan prácticamente indiscernibles. Esta estrategia hace que la reproducción se convierta en un síntoma, en un índice que apunta más allá de la duplicación -a la posibilidad de generar una comunidad basada en los medios de cultura masivos-, pero sin salirse de ella.

\section{REFERENCIAS}

Alonso, Carlos. 1985. "La guaracha del Macho Camacho. The Novel as Dirge". MLN. Vol. 100, № 2, pp. 348-360.

Amar Sánchez, Ana María. 2000. Juegos de seducción y traición. Literatura y cultura de masas. Buenos Aires, Argentina: Beatriz Viterbo Editora.

Chadwick, Joseph. 1987. “'Repito para consumo de los radioyentes': Repetition and Fetishism in La guaracha del Macho Camacho". Revista de Estudios Hispánicos. Tomo XXI, № 2, pp. 61-83.

Chion, Michel. 2008. La audiovisión. Buenos Aires, Argentina: Paidós.

Cruz, Arnaldo. 1985. "Repetition and the Language of the Mass Media in Luis Rafael Sanchez's La guaracha del Macho Camacho". Latin American Literary Review, Vol. XIII, No 26, pp. 35-48.

De Certeau, Michel.1999. La invención de lo cotidiano. México D.F., México: Universidad Iberoamericana.

Feliú, Fernando. 2001. "Del ritmo en clave de un disco rayado: La guaracha del Macho Camacho en un pentagrama". Revista de Estudios Hispánicos. Vol 27, 
No 2, pp. 223-240.

Fernández, José Luis (Ed.). 2008. La construcción de lo radiofónico. Buenos Aires, Argentina: Editorial La Crujía Ediciones.

Gallo, Rubén. 2005. Mexican Modernity. Cambridge, M.A., Estados Unidos: MIT Press.

Kressner, Ilka. 2008. "Emisiones poderosas: el impacto de la radio en Pantaleón y las visitadoras y La guaracha del Macho Camacho". Hispanófila No 152, pp. 101-113.

Martín Barbero, Jesús. 2001. De los medios a las mediaciones. Comunicación, cultura y hegemonía. $6^{a}$ edición. Madrid, España: Gustavo Gili Ediciones.

McLuhan, Marshall. 1964. Understanding Media. New York, Estados Unidos: Mentor Books.

Sánchez, Luis Rafael. 2000. La guaracha del Macho Camacho. Madrid, España: Cátedra.

Santos, Lidia. 2001. Kitsch tropical. Los medios en la literatura y el arte de América Latina. Madrid, España: Editorial Vervuert. 